\title{
Evaluation of the Involvement of Facial and Cervical Spaces in Odontogenic Infections in Patients Referred to Shahid Rahnemoon Hospital from 2014 to 2018
}

\author{
Mohsen Barzegar ${ }^{1}$, Amir Vaghefi², Adele Pouyafard ${ }^{3}$, Seyed Mojtaba Alavikia ${ }^{4}$ \\ 1,4 Department of Oral and Maxillofacial Surgery, School of Dentistry, Shahid Sadoughi University of Medical Science, \\ Yazd, Iran. ${ }^{2}$ Department of Dentistry, School of Dentistry, Shahid Sadoughi University of Medical Science, Yazd, Iran. \\ ${ }^{3}$ Department of Oral Medicine, School of Dentistry, Shahid Sadoughi University of Medical Science, Yazd, Iran.
}

\section{ABSTRACT}

\section{BACKGROUND}

Odontogenic infections are recognized as one of the most common diseases in the world. Organisms that cause dental infection and are a part of the oral normal flora include dental plaque bacteria, mucosal surface bacteria, and gingival bacteria. This study aimed to investigate the prevalence of odontogenic infections by involving the facial and cervical spaces in patients referred to Shahid Rahnemoon Hospital from 2014 to 2018.

\section{METHODS}

This was a descriptive cross-sectional study. The sampling method was census and 308 patients with all types of odontogenic infections associated with the involvement of the facial and cervical spaces referred to Shahid Rahnemoon Hospital from 2014 to 2018 were included in the study. Questionnaire was used for data collection. The data was entered into SPSS version 23 software and analysed using statistical tests.

\section{RESULTS}

The mean age of participants was $31.10 \pm 14.48$; the mean number of hospitalization days was $4.83 \pm 2.52$ days; the mean body temperature was $37.45 \pm 0.54$. Of the 308 patients studied, 221 (71.8\%) had no history of systemic disease. Also, 294 (5\%) had no airway involvement. The most commonly prescribed antibiotic was penicillin + metronidazole with a frequency of $54.9 \%$, The most common tooth that was the source of infection was mandibular tooth no. 6 with a frequency of $22.7 \%$, the most common type of treatment was incision + drainage + antibiotic therapy with a frequency of $44.2 \%$; the most common involved area was the submandibular + buccal space with a frequency of $20.1 \%$ and the most common age range of involvement was 20 - 29 years.

\section{CONCLUSIONS}

In odontogenic infections, penicillin + metronidazole is the most commonly used antibiotic and buccal + submandibular space is the most common area involved.

\section{KEY WORDS}

Odontogenic Infection, Facial Spaces, Cervical Spaces
Corresponding Author:

Dr. Amir Vaghefi,

Department of Dentistry,

School of Dentistry,

Shahid Sadoughi University of

Medical Science, Yazd, Iran.

E-mail: amirvaghefi73@gmail.com

DOI: $10.14260 / j e m d s / 2020 / 649$

How to Cite This Article:

Barzegar M, Vaghefi A, Pouyafard A, et al. Evaluation of the involvement of facial and cervical spaces in odontogenic infections in patients referred to Shahid Rahnemoon hospital from 2014 to 2018. J Evolution Med Dent Sci 2020;9(40):2960-2964, DOI: $10.14260 /$ jemds/2020/649

Submission 01-07-2020,

Peer Review 25-08-2020

Acceptance 02-09-2020,

Published 05-10-2020.

Copyright (c) 2020 Mohsen Barzegar et al. This is an open access article distributed under Creative Commons Attribution License [Attribution 4.0 International (CC BY 4.0)] 


\section{BACKGROUND}

Infections in the oral cavity are often of dental origin and are called odontogenic infections. These infections include dental caries, periapical abscesses, gingivitis and periodontitis. Odontogenic infections are known to be one of the most common diseases in the world, and the most important reason that prompts the patient to seek dental care.1,2 One of the important factors in the incidence of dental infections is the status of the host immune system and its ability to cope with infection, and among the factors affecting the body's immune system are uncontrolled metabolic diseases such as diabetes. ${ }^{3}$ Odontogenic infections are diseases that are caused by the activity of several bacterial species and are called polymicrobial bacteria.4,5 Organisms that cause dental infection are a part of the oral normal flora, include dental plaque bacteria, mucosal surface bacteria and gingival bacteria. These bacteria are the ones that cause dental caries, gingivitis and periodontitis. Most bacteria that cause odontogenic infections are Staphylococcus epidermidis, alpha haemolytic Streptococcus and haemolytic Streptococcus. ${ }^{6}$

Untreated dental infections pierce the thinnest part of the bone and transfer to adjacent tissues. These infections, if originated from the maxillary teeth, spread to the vestibular, buccal, subcutaneous, infraorbital, palatal, infratemporal spaces and maxillary sinus. If they originate from the mandibular teeth, they spread to the vestibular, buccal, submandibular, sublingual, and submental spaces. ${ }^{7}$ Most odontogenic infections originate from the mandibular third molar followed by the mandibular second molar, and most of the involvement is related to the submandibular space. ${ }^{8}$ Treatment of odontogenic infections is one of the issues in dentistry. Treatment of these infections may be through medication, surgery, or both. ${ }^{9}$ The first line of antibiotic treatment for dental infections is penicillin. Metronidazole is also prescribed to kill streptococcal bacteria and anaerobes. Because second-generation cephalosporins have fewer side effects and are more potent than penicillin, they are prescribed in combination with metronidazole. ${ }^{10}$

Drainage and removal of the infectious agent is another way of treating dental infections. ${ }^{11}$ In very severe cases, rapid surgical intervention and hospitalization in the intensive care unit may be required to prevent the spread of infection to the skull and the paratracheal space leading to airway closure, and the length of hospital stay depends on the severity of the infection and the systemic condition of the individual. ${ }^{12}$ Untreated or late treatment can lead to life-threatening complications such as airway obstruction, necrotizing fasciitis, mediastinitis, pericarditis, rupture of the arteries, brain abscess and sepsis. ${ }^{13}$ In 2013, Pourdanesh et al. in Iran conducted a study on the pattern of odontogenic infection in a Tehran hospital by reviewing the records of 310 patients. In this study, patients were between 2 and 84 years of age, and $62.6 \%$ of patients with odontogenic infection were younger than 35 years. The most commonly used antibiotics were metronidazole and penicillin $\mathrm{G}$ or cefazolin and metronidazole. The mortality rate due to Ludwig's angina was $1 \%{ }^{6}$

Igoumenakis et al., in a study on severe dental infections, the causes of their spread and management of them at Attica General Hospital in Greece in 2014, examined all patients with severe dental infections with the help of information contained in their records. Drainage was seen in $63.2 \%$ of patients, and in $46.2 \%$ of patients their infected tooth was extracted. There was a significant relationship between fever and length of hospital stay, but no significant complications were seen in these patients. ${ }^{14}$

Kataria et al. conducted a retrospective study on the prevalence of odontogenic deep neck space infections for 76 people with DNSI in India in 2015. 34.21\% of these infections were of dental origin. Submandibular infection with the prevalence of $42.3 \%$ was the most common clinical symptom in these patients, followed by Ludwig's angina and masseteric abscess. ${ }^{15}$

Bahl et al., in 2017, conducted a study in India on dental infections, their microbiology and management. In this study, which studied 100 patients younger than 60 years, the mandibular third molar followed by the mandibular second molar were the main cause of the infection, with submandibular space most affected. Co-amoxiclav and metronidazole are prescribed to treat these infections. According to this study, drainage was performed after the extraction of the infected tooth. ${ }^{8}$

The purpose of this study was to evaluate the characteristics of odontogenic infection with involvement of facial and cervical spaces, such as age and gender of affected individuals, source of infection, involved spaces, type of treatment and antibiotic prescribed, systemic disease history, airway involvement, body temperature and the length of hospital stay.

\section{METHODS}

This study was a descriptive cross-sectional study. The statistical population of this study consisted of 386 patients with various types of odontogenic infections associated with the involvement of facial and cervical spaces, referred to Shahid Rahnemoon Hospital during the period of 2014 - 2018. The sampling method was census, and all patients with all types of odontogenic infections associated with the involvement of facial and cervical spaces referred to Shahid Rahnemoon Hospital were included in the study, and patients with incomplete and inaccessible information, were excluded. Data were collected by referring to Shahid Rahnemoon Hospital archive. Questionnaire was used to collect data, and information included age, sex, source of infection, involved facial and cervical spaces, and type of antibiotic prescribed, type of treatment, history of previous illness, airway involvement, body temperature and length of hospitalization.

Finally, the data was entered into SPSS software version 23, and descriptive statistics including mean, standard deviation, tables and frequency distribution charts were used to analyze the data. Chi-square and Fisher exact tests were used to compare frequency distributions. Significance level is considered less than 0.05 .

Given that the study was based on a checklist completed by the researcher and as a cross-sectional study, no consideration was done; except to safeguard patient secrets in accordance with the Helsinki Treaty, and people are assured that their information will be confidential and only be used for research purposes. Also, no additional costs will be incurred in the implementation of this study. Also, the aforementioned proposal in the Ethics Committee of Shahid Sadoughi 
University of Medical Sciences with ethic code IR.SSU.REC.1397.045 has been approved and agreed.

\section{RESULTS}

The aim of this study was to investigate the prevalence of odontogenic infections associated with the involvement of the facial and cervical spaces in patients referred to Shahid Rahnemoon Hospital. This study was performed on 386 patients with odontogenic infections, of which 78 samples had incomplete records, and finally, the study was performed on 308 patients. Of these patients, 165 (53.6\%) were male and $143(46.4 \%)$ were female.

The results of descriptive indices of variables of age, number of days of hospitalization and body temperature showed that the mean age of participants was $31.10 \pm 14.48$. The results of the study of frequency distribution of systemic disease history or systemic conditions affecting the treatment of odontogenic infection showed that out of 308 patients, 221 (71.8\%) had no specific disease history. The results of the study of frequency distribution of antibiotics prescribed in the studied patients showed that out of 308 patients, 169 (54.9\%) were treated with penicillin + metronidazole (Table 1).

\begin{tabular}{|ccc|}
\hline Prescribed Antibiotic & Frequency & Percentage \\
Clindamycin & 42 & 13.6 \\
Penicillin + Metronidazole & 169 & 54.9 \\
Clindamycin + & 69 & 22.4 \\
Metronidazole & 28 & 9.1 \\
Cefazolin + Metronidazole & $\mathbf{3 0 8}$ & $\mathbf{1 0 0}$ \\
\hline Total & Table 1. Frequency Distribution of Antibiotics Prescribed in Patients \\
\hline
\end{tabular}

The results of the study of frequency distribution of airway involvement in the studied patients showed that out of 308 patients, 294 (95 / $5 \%$ ) had no airway involvement and 14 (4 / $5 \%$ ) had airway involvement.

The results of the study of frequency distribution of type of treatment in the studied patients showed that of 308 patients, $136(44.2 \%)$ were treated with incision + drainage + antibiotic therapy (Table 2).

\begin{tabular}{|ccc|}
\hline Type of Treatment & Frequency & Percentage \\
Antibiotic Therapy & 89 & 28.9 \\
Extraction & 4 & 1.3 \\
$\begin{array}{c}\text { Incision + Drainage + } \\
\text { Antibiotic Therapy }\end{array}$ & 136 & 44.2 \\
$\begin{array}{c}\text { Incision + Drainage + } \\
\text { Antibiotic Therapy + } \\
\text { Extraction }\end{array}$ & 48 & 15.6 \\
$\begin{array}{c}\text { Root canal Treatment + } \\
\text { Antibiotic Therapy } \\
\text { Incision + Drainage + } \\
\text { Antibiotic Therapy + } \\
\text { Rootcanal Treatment } \\
\text { Total }\end{array}$ & 18 & 5.8 \\
\hline Table 2. Frequency Distribution of the Type of Treatment in Patients \\
\hline
\end{tabular}

The results of the study of frequency distribution of involved space in the studied patients showed that out of 308 patients, $62(20.1 \%)$ had the involvement of submandibular + buccal space (Table 3 ).

The results of the study of frequency distribution of body temperature in the studied patients showed that out of 308 patients, 167 (54.2\%) had a body temperature ranged between $37-37.5^{\circ} \mathrm{C}$ (Table 4).

\begin{tabular}{|c|c|c|}
\hline Involved Space & Frequency & Percentage \\
\hline Buccal & 20 & 6.5 \\
\hline Submandibular & 14 & 4.5 \\
\hline Submental & 2 & 0.6 \\
\hline Infraorbital & 6 & 1.9 \\
\hline Canine & 1 & 0.3 \\
\hline Temporal & 1 & 0.3 \\
\hline Pterygomandibular & 14 & 4.5 \\
\hline Vestibular & 4 & 1.3 \\
\hline Sublingual & 4 & 1.3 \\
\hline Ludwig's angina & 4 & 1.3 \\
\hline Palatal & 3 & 1 \\
\hline $\begin{array}{l}\text { Submandibular }+ \\
\text { Pterygomandibular }\end{array}$ & 16 & 5.2 \\
\hline Submandibular + Submental & 4 & 1.3 \\
\hline Submandibular + Sublingual & 3 & 1 \\
\hline $\begin{array}{l}\text { Submandibular }+ \\
\text { Submasseteric }\end{array}$ & 10 & 3.2 \\
\hline Buccal + Pterygomandibular & 5 & 1.6 \\
\hline Buccal + Submandibular & 62 & 20.1 \\
\hline Buccal + Submasseteric & 14 & 4.5 \\
\hline $\begin{array}{l}\text { Pterygomandibular + } \\
\text { Submasseteric }\end{array}$ & 1 & 0.3 \\
\hline $\begin{array}{c}\text { Pterygomandibular + Lateral } \\
\text { pharyngeal }\end{array}$ & 1 & 0.3 \\
\hline Submental + Sublingual & 1 & 0.3 \\
\hline Submandibular + Vestibular & 44 & 14.3 \\
\hline Infraorbital + Vestibular & 14 & 4.5 \\
\hline $\begin{array}{c}\text { Buccal }+ \text { Submandibular }+ \\
\text { Vestibular }\end{array}$ & 2 & 0.6 \\
\hline Buccal + Infraorbital & 55 & 17.9 \\
\hline Infraorbital + Canine & 1 & 0.3 \\
\hline Total & 308 & 100 \\
\hline
\end{tabular}

\begin{tabular}{|ccc|}
\hline Body Temperature & Frequency & Percentage \\
$36-36.9$ & 28 & 9.1 \\
$37-37.5$ & 167 & 54.2 \\
$37.6-38$ & 73 & 23.7 \\
$38.1-38.5$ & 31 & 10.1 \\
$\geq 38.6$ & 9 & 2.9 \\
Total & 308 & 100 \\
\hline Table 4. Frequency Distribution of Body Temperature in Patients \\
\hline
\end{tabular}

The results of the study of frequency distribution of systemic disease history by gender in the studied patients showed that out of 221 patients who did not have systemic disease, 124 (75.2 \%) were male and 97 (67.8\%) were female.

The analysis using Chi-square test showed that there was no statistically significant difference between the frequency distribution of systemic disease history by gender in the studied patients $(\mathrm{p}>0.05)$.

The results of the study of frequency distribution of airway involvement by gender in the studied patients showed that out of 294 patients who did not have airway involvement, 159 (96.4\%) were male and 135 (94.4\%) were female. Further information is provided in Table 5.

\begin{tabular}{|c|c|c|c|}
\hline \multirow{2}{*}{$\begin{array}{c}\text { Airway } \\
\text { Involvement }\end{array}$} & \multicolumn{2}{|c|}{ Gender } & \multirow{2}{*}{ Total } \\
\hline & Man & Woman & \\
\hline Does not have & $159(96.4 \%)$ & 135 (94.4 \%) & $294(95.5 \%)$ \\
\hline Has & $6(3.6 \%)$ & $8(5.6 \%)$ & $14(4.5 \%)$ \\
\hline Total & $165(100 \%)$ & $143(100 \%)$ & $308(100 \%)$ \\
\hline P-Value & 0.411 & & \\
\hline Table 5 & $\begin{array}{l}\text { uency Distr } \\
\text { by Gend }\end{array}$ & $\begin{array}{l}\text { of of Airway } \\
\text { Patients }\end{array}$ & ement \\
\hline
\end{tabular}

The analysis of Table 5 using Chi-square test showed that there was no statistically significant difference between the frequency distribution of airway involvement by gender in the studied patients $(\mathrm{p}>0.05)$. 
The results of the study of frequency distribution of body temperature by gender in the studied patients showed that out of the 167 patients with a body temperature between 37 $37.5^{\circ} \mathrm{C}, 88(53.3 \%)$ were male and 79 (55.2 \%) were female.

The analysis using Chi-square test showed that there was no statistically significant difference between the frequency distribution of body temperature by gender in the studied patients $(p>0.05)$.

\section{DISCUSSION}

Infections in the oral cavity are often of dental origin and are called odontogenic infections. Most bacteria that cause odontogenic infections are Staphylococcus epidermidis, alpha haemolytic Streptococcus and haemolytic Streptococcus. ${ }^{6}$ The prevalence of odontogenic infections has been varied in different studies. In the Wang study of the 250 studied patients with maxillofacial infections, in 157, the infection had a dental origin (63\%). ${ }^{16}$ In another study conducted in 2012, out of 297 hospitalized patients, 102 (34.3\%) had head and neck infections of dental origin. ${ }^{17}$ In another study in India, the prevalence of odontogenic infections was $34.21 \% .15$ Odontogenic infections also have morbidity and mortality in addition to relatively high prevalence of infections involving the facial spaces. A study in Brazil found that mortality was high when the infection was associated with septic shock and mediastinitis.

The mortality rate in this study was $2.11 \%$, and out of 5 patients with mediastinitis, one person died. ${ }^{18}$ In another study in Shiraz, one person died $(0.9 \%) .{ }^{17}$ In a study by Pourdanesh, the mortality rate due to Ludwig's angina was 1 $\% .{ }^{6}$ No mortality was observed in our study, which could be due to timely diagnosis and appropriate treatment plans as well as regular follow-up of patients.

Due to the relatively high prevalence of odontogenic infections and the presence of mortality in patients with these infections, treatment and choosing the right treatment and antibiotic in these patients are of great importance. Therefore, our study aimed to investigate the prevalence of odontogenic infections with the involvement of facial and cervical spaces.

The results of our study showed that the mean age of participants was $31.10 \pm 14.48$ with the minimum age of 4 and the maximum age of 85 years. Also, the most common age range of patients was 20 - 29 years with a frequency of $30.2 \%$. In a study by Sanches, the mean age of patients was 40.3 years. ${ }^{19}$ In a study by Pourdanesh, patients were between the ages of 2 to 84 years, and $62.6 \%$ of patients with odontogenic infection were younger than 35 years. ${ }^{6}$ In another study performed in Greece, the mean age was 40.8 years. ${ }^{14}$ Overall, odontogenic infections occur most often in the decades of 3 and 4 of life, at a young age. This may be because dental caries, which is a risk factor for odontogenic infections, is more common at a young age. Regarding the gender distribution in our study, of the 308 patients studied, 165 (53.6\%) were male and 143 (46.4\%) were female. In the Wang study, of the 157 patients studied, 102 were male and 55 were female, and the incidence was higher in men. ${ }^{16}$ But in a study conducted in 2011, the incidence of odontogenic infections in both men and women was moderate (a slight incidence in men). ${ }^{19}$ In the study by Pourdanesh, $57.1 \%$ of patients were male and $42.9 \%$ were female. ${ }^{6}$ Overall, although odontogenic infections were higher in men than in women, this difference was not statistically significant.

Concerning the length of hospital stay, the mean length of stay in our study was $4.83 \pm 2.52$ days with a minimum duration of 1 and a maximum duration of 16 days. In the Wang study, the length of hospital stay varied from 1 to 23 days, and only one patient needed hospitalization again. ${ }^{16}$ In the Kim study, the mean hospital stay was 3.9 days. About $88 \%$ of discharges were performed regularly after treatment, and only $2 \%$ of patients were transferred to other hospitals. ${ }^{20}$ The mean body temperature in our study patients was $37.45 \pm$ $0.54^{\circ} \mathrm{C}$, and $54.2 \%$ of patients had a body temperature with a range between $37-37.5^{\circ} \mathrm{C}$. This finding is consistent with the results of the study by Pourdanesh, in which the majority of patients (46.4\%) had a body temperature of $37-37.5^{\circ} \mathrm{C} .6^{6}$

Concerning the frequency of the tooth that was the source of infection, the results of our study showed that the most common tooth that was the source of infection was mandibular tooth no. 6 with a frequency of $22.7 \%$, followed by mandibular tooth no. 7 with a frequency of $13 \%$. A study by Rashi found that the mandibular third molar followed by the mandibular second molar were the main cause of infection. ${ }^{8}$ The Sanches study noted that the most important cause of infection is the tooth decay of the posterior part of the mandible. ${ }^{20}$ In the study by Pourdanesh, the most involved tooth was the mandibular third molar. ${ }^{6}$ Overall, it can be argued that the involvement of facial and cervical spaces following odontogenic infections originating from mandibular teeth is far more infectious than those originating from maxillary teeth.

In the Kataria study, the infected submandibular space with the prevalence of $42.3 \%$ was the most common space involved (47). In the Rashi study also, the submandibular space was the most common space involved. ${ }^{6}$

The most common antibiotics used in the study by Pourdanesh were metronidazole and penicillin G or cefazolin and metronidazole. ${ }^{6}$ In a study in Greece, drainage was seen in $63.2 \%$ of patients, and in $46.2 \%$ of patients, their infected tooth was extracted. ${ }^{14}$ In the Rashi study, both aerobic and anaerobic bacteria grew in $60 \%$, in $15 \%$, only aerobic bacteria and in the rest, only anaerobic bacteria grew. Streptococcus viridans is the most common bacteria among aerobic bacteria, and bacteroides and prevotella are the most common bacteria among anaerobic bacteria. Co-amoxiclav and metronidazole are prescribed to treat these infections. According to this study, drainage was performed after the extraction of the infected tooth. ${ }^{8}$ On the whole, odontogenic infections can be treated with penicillin at the forefront of antibiotic treatment of dental infections. Metronidazole is also prescribed to kill streptococcal bacteria and anaerobes. Because secondgeneration cephalosporins have fewer side effects and are more potent than penicillin, they are prescribed in combination with metronidazole. ${ }^{10}$

\section{CONCLUSIONS}

According to the results of our study, it can be concluded that odontogenic infections occur mostly in young people (with an age range of $20-29$ years) and patients with no history of 
systemic disease and the most common antibiotic prescribed in these patients is penicillin + metronidazole. The most common tooth that is the source of odontogenic infection is also the mandibular tooth no. 6 and the most common facial and cervical space involved in odontogenic infections is the buccal + submandibular space. The most common treatment is incision + drainage + antibiotic therapy.

Financial or Other Competing Interests: None.

\section{REFERENCES}

[1] Chow AW. Infections of the oral cavity, neck, and head. In: Mandell GL, Douglas RG, Bennett JE, eds. Principles and practice of infectious diseases. Toronto: Churchill Livingstone 2000:689-98.

[2] Matesanz P, Figuero E, Jiménez MJ, et al. From knowledge of bacterial etiology to the treatment and prevention of the most prevalent infections in the community: odontological infections. Rev Esp Quimioter 2005;18(2):136-45.

[3] Tierney MR, Baker AS. Infection of head and neck in diabetes mellitus. Infect Dis Clin North Am 1995;9(1):195-216.

[4] Kolenbrander PE, Palmer RJ, Richard AH, et al. Bacterial interactions and successions during plaque development. Periodontol 2000 2006;42:47-79.

[5] Socransky SS, Haffajee A. The bacterial etiology of destructive periodontal disease: current concepts. J Periodontol 1992;63(4 Suppl):322-31.

[6] Pourdanesh F, Dehghani N, Azarsina M, et al. Pattern of odontogenicinfections at a tertiary hospital in Tehran, Iran: a 10 - year retrospective study of 310 patients. J Dent (Tehran) 2013;10(4):319-28.

[7] Miloro M, Ghali GE, Larsen P, et al. Peterson's principles of oral and maxillofacial surgery. USA: PMPH 2004.

[8] Bahl R, Sandhu S, Singh K, et al. Odontogenic infections: microbiologyand management. Contemp Clin Dent 2014;5(3):307-11.

[9] Guzmán-Letelier M, Crisosto-Jara C, Diaz-Ricouz C, et al.
Severe odontogenic infection: an emergency. Case report. J Clin Exp Dent 2017;9(2):e319-24.

[10] Al-Qamachi LH, Aga H, McMahon J, et al. Microbiology of odontogenic infections in deep neck spaces: a retrospective study. Br J Oral Maxillofac Surg 2010;48(1):37-9.

[11] Rastenienè R, Aleksejūnienè J, Pūrienè A. Determinants of length of hospitalization due to acute odontogenic maxillofacial infections: a 2009 - 2013 retrospective analysis. Med Princ Pract 2015;24(2):129-35.

[12] DeAngelis AF, Barrowman RA, Harrod R, et al. Maxillofacial emergencies: oral pain and odontogenic infections. Emerg Med Australas 2014;26(4):336-42.

[13] Zhang C, Tang Y, Zheng M, et al. Maxillofacial space infection experience in West China: a retrospective study of 212 cases. Int J Infect Dis 2010;14(5):e414-7.

[14] Igoumenakis D, Gkinis G, Kostakis G, et al. Severe odontogenic infections: causes of spread and their management. Surg Infect (Larchmt) 2014;15(1):64-8.

[15] Kataria G, Saxena A, Bhagat S, et al. Prevalence of odontogenic deep neck space infections (DNSI): a retrospective analysis of 76 cases of DNSI. Int J Otorhinolaryngol Head Neck Surg 2015;1(1):11-6.

[16] Wang J, Ahani A, Pogrel MA. A five-year retrospective study of odontogenic maxillofacial infections in a large urban public hospital. Int J Oral Maxillofac Surg 2005;34(6):646-9.

[17] Zamiri B, Hashemi SB, Hashemi SH, et al. Prevalence of odontogenic deep head and neck spaces infection and its correlation with length of hospital stay. Shiraz Univ Dent 2012;13(1):29-35.

[18] Suehara AB, Gonçalves AJ, Alcadipani FAMC, et al. Deep neck infection: analysis of 80 cases. Braz J Otorhinolaryngol 2008;74(2):253-9.

[19] Sánchez R, Mirada E, Arias J, et al. Severe odontogenic infections: epidemiological, microbiological and therapeutic factors. Med Oral Patol Oral Cir Bucal 2011;16(5):e670-6.

[20] Kim MK, Nalliah RP, Lee MK, et al. Factors associated with length of stay and hospital charges for patients hospitalized with mouth cellulitis. Oral Surg Oral Med Oral Pathol Oral Radiol 2012;113(1):21-8. 